\title{
Rhythmic morphology in a microtidal low-energy beach
}

\section{Anna Mujal-Colilles $1^{\mathrm{a}}$.}

anna.mujal@upc.edu

Manel Grifoll1르

Albert Falquészำ

‡a:Laboratori d"-Enginyeria Marítima, Department of Civil and Environmental Engineering, UPC-Barcelona Tech, C/ Jordi Girona, 1-3, 08034 Barcelona, Spain

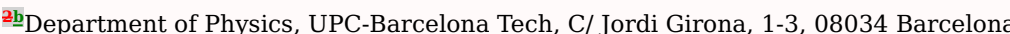

*Corresponding author.

\section{Abstract}

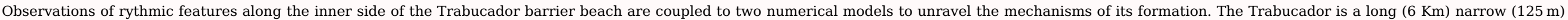

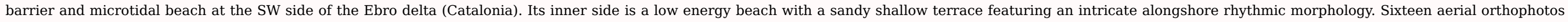

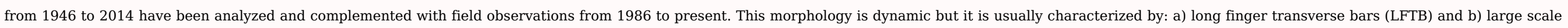

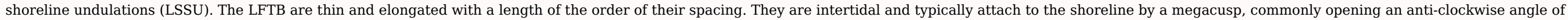

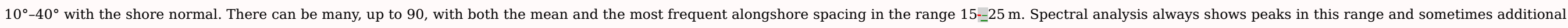

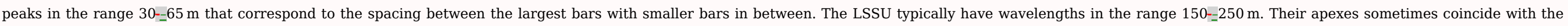

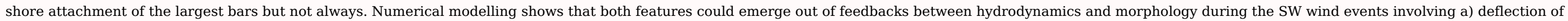
the longshore current by the bars combined with the refractive wave focusing and b) gradients in total alongshore sediment transport rate triggering the high-angle wave instability.

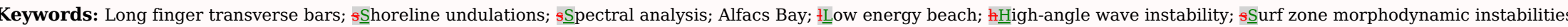

\subsection{Introduction}

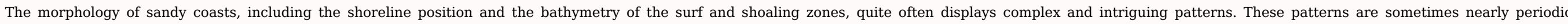

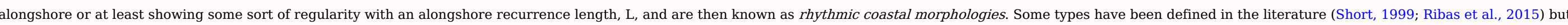
the extreme complexity of beach dynamics and the increasing capacity and frequency of beach monitoring and field observations often challenge their traditional classification (Guillén et al., 2017).

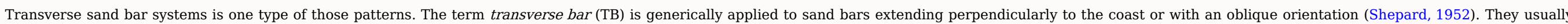

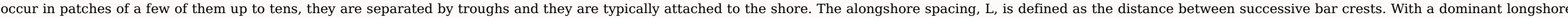

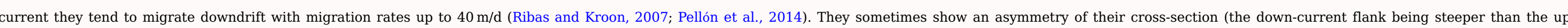
current flank, Pellón et al., 2014).

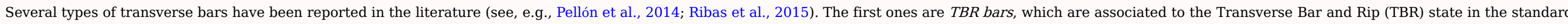

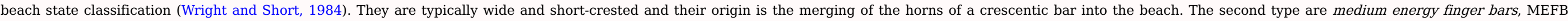

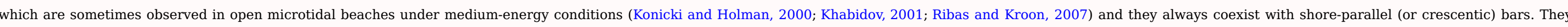

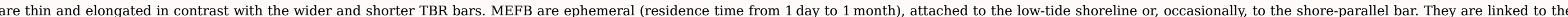




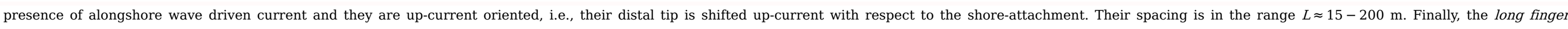

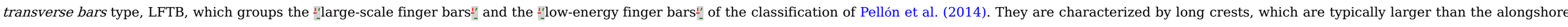

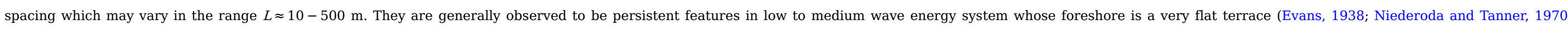

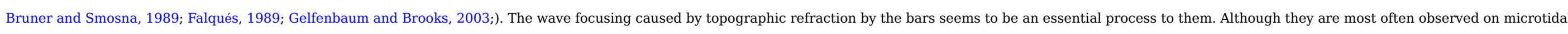
beaches, they may also exist on meso and macrotidal coasts (Levoy et al., 2013; Pellón et al., 2014). They tend to be oriented almost perpendicular to the shore or with a small angle.

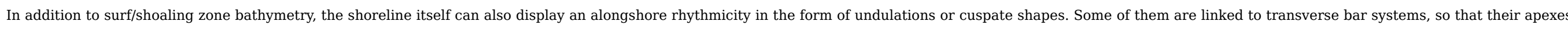

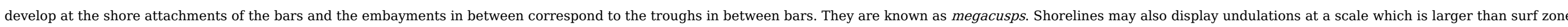

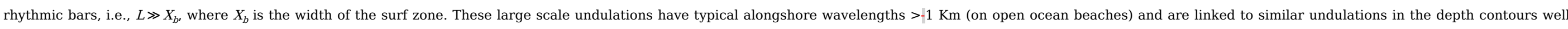
offshore the surf zone. They have been called Km-scale shoreline sand waves (Idier and Falqués, 2014).

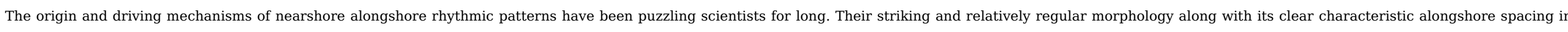

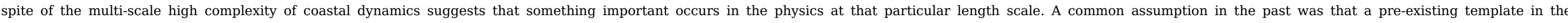

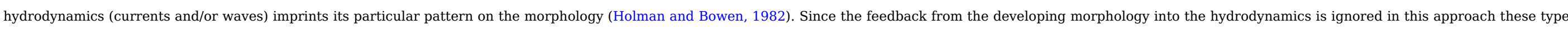

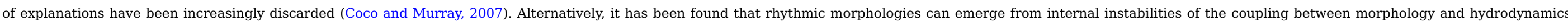

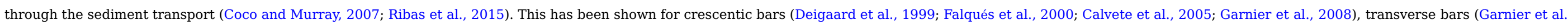

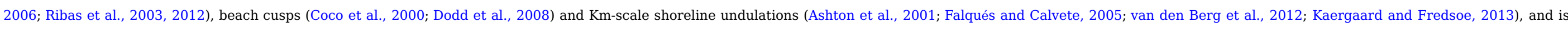
known as the self-organization theory.

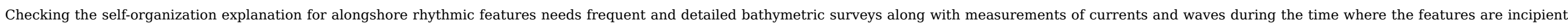

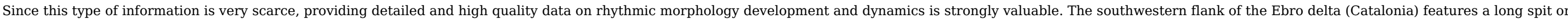

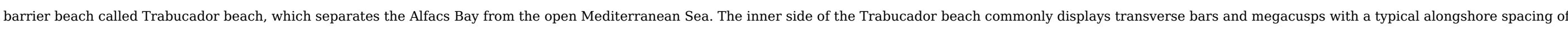

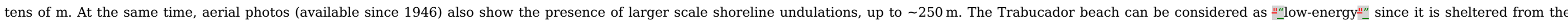
open sea waves. A preliminary description of this system was done by Falqués (1989)

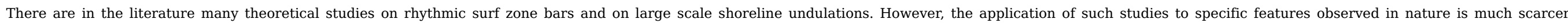

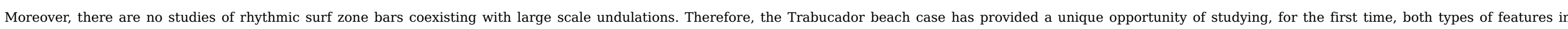
coexistence and from both views: observations and modelling.

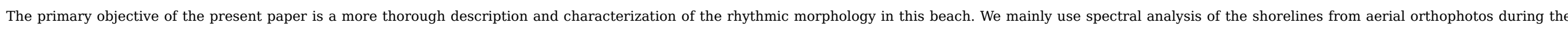

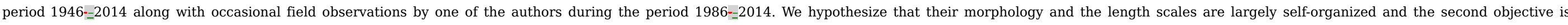
investigating the physical mechanisms driving its formation and dynamics by means of numerical modelling.

\subsection{Study Area and morphology}

\subsubsection{Geographical setting and meteo-oceanographic conditions}

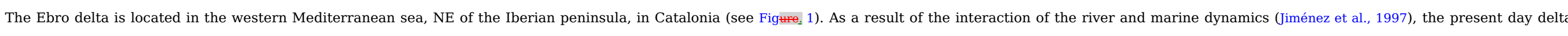

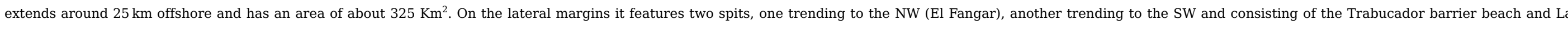

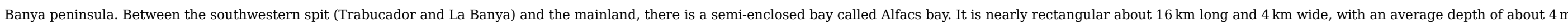

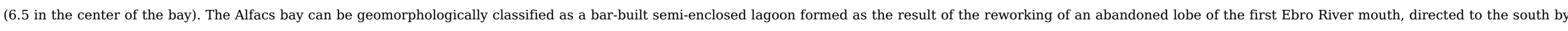

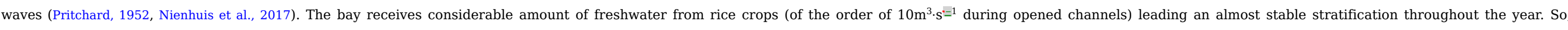

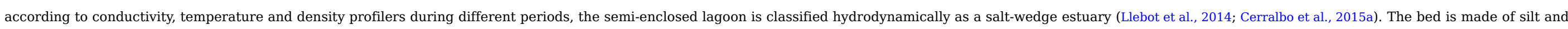




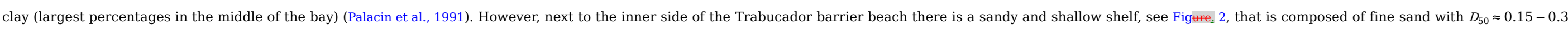
$\mathrm{mm}$ (Falqués, 1989). This shelf deepens from 0 to roughly $0.7 \mathrm{~m}$ within about $125 \mathrm{~m}$ width and, presumably, it has been built out of sediments from the outer side of the beach during overwash events.
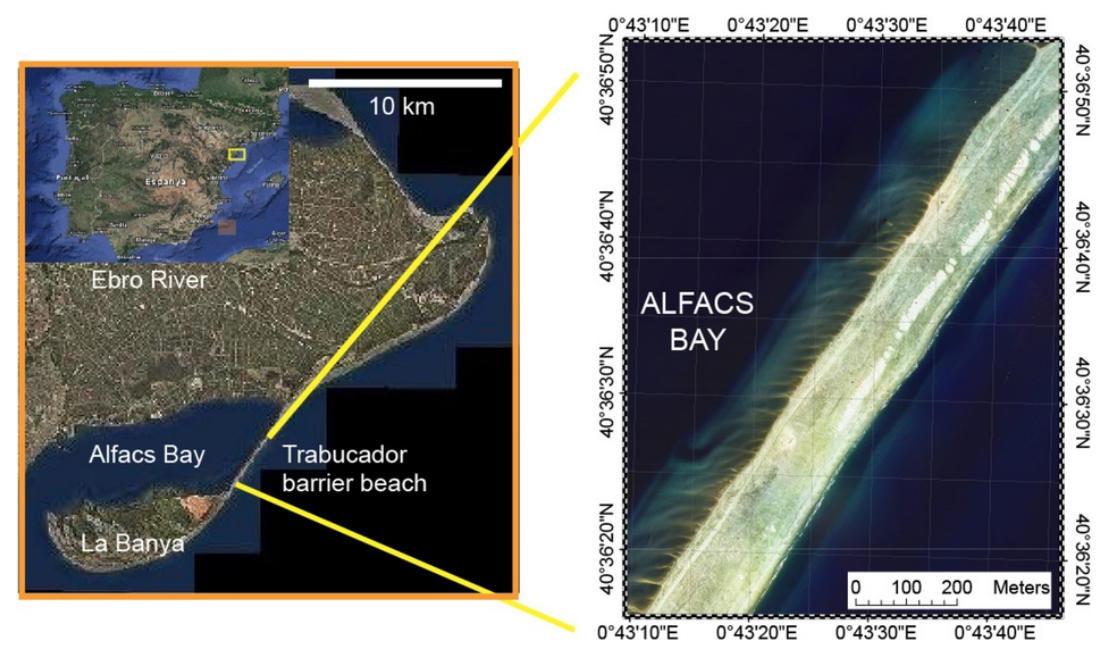

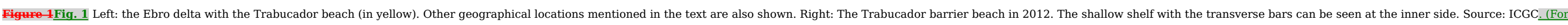
interpretation of the references to colour in this figure lecend, the reader is referred to the web version of this article.)

\section{alt-text: Fig. 1}

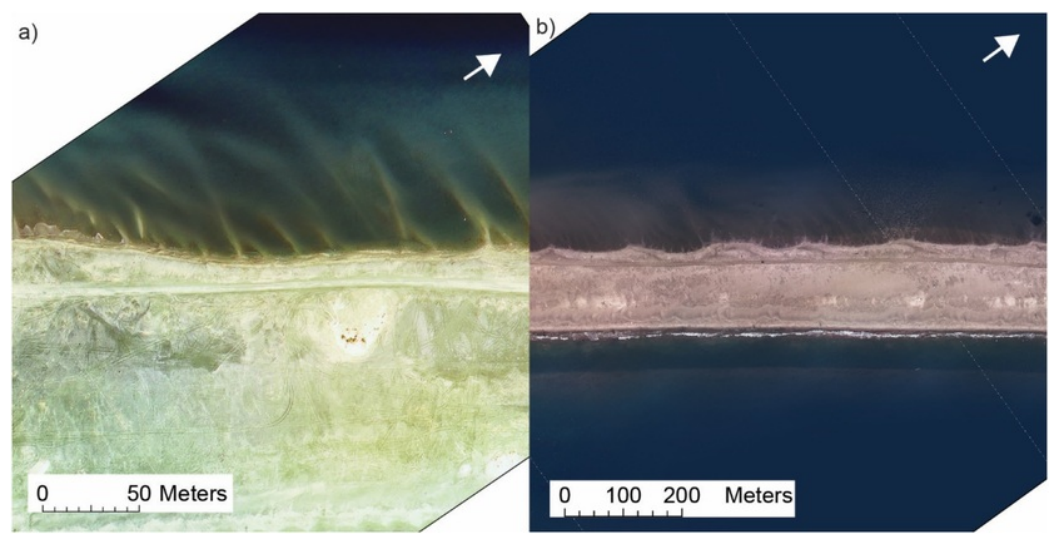

Figure 2Fiq. 2 a) Detailed view of the transverse bar system in 2012. b) View of the inner Trabucador beach in 2013 where the large scale undulations are visible. Source: ICGC. White arrow represents the North_. alt-text: Fig. 2

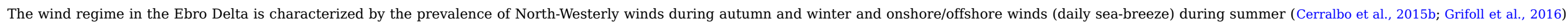

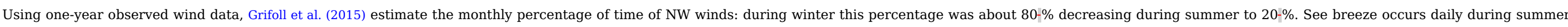

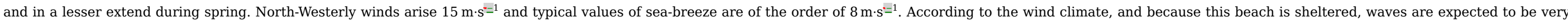
small in comparison to the open-sea side of the Trabucador.

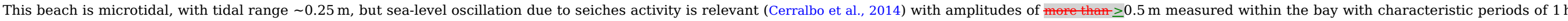

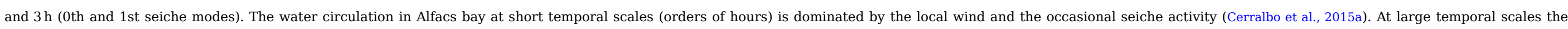




\subsubsection{The alongshore rhythmic morphological system}

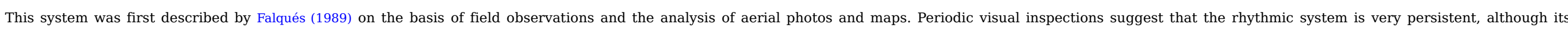

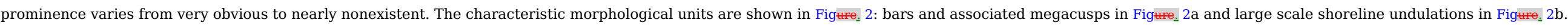

\subsection{Bars and megacusps}

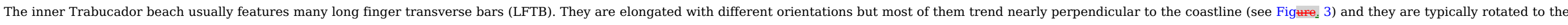

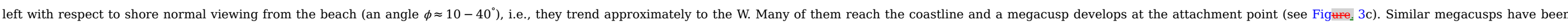
described by Evans $(1939,1938)$. 


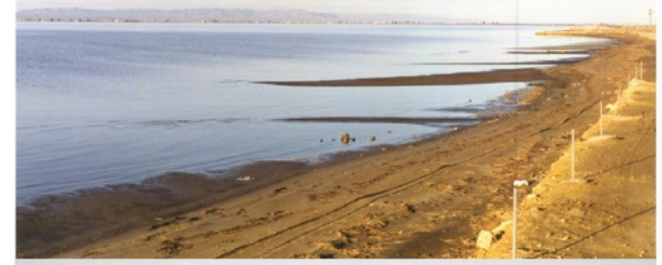

(b)

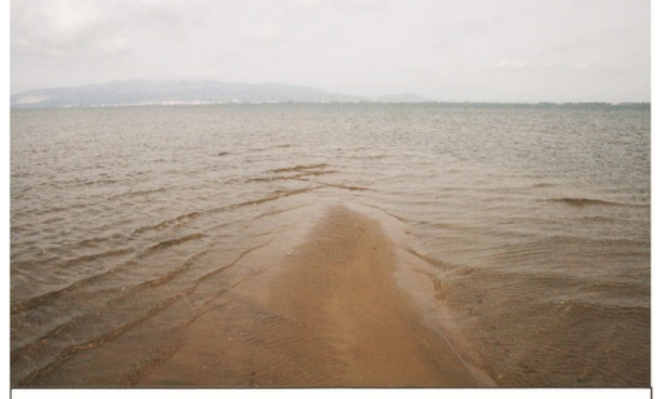

(c)

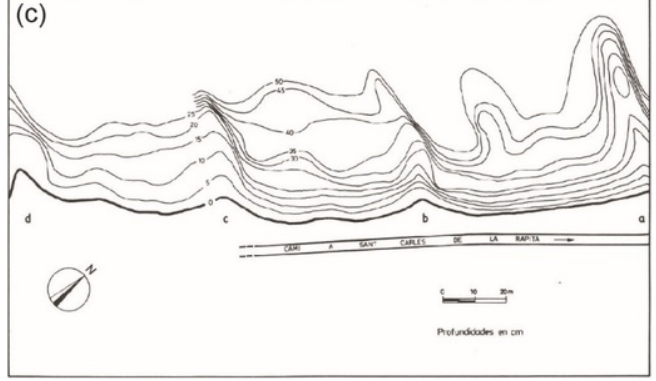

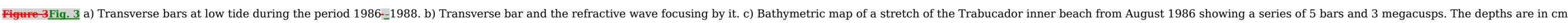
alt-text: Fig. 3

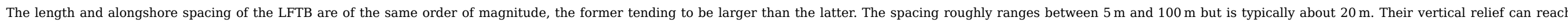

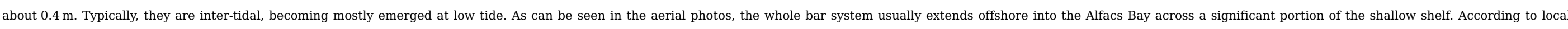
fishermen, the bars have been there for, at least, the last 70 years. Indeed, they are already visible in an aerial photo of 1946 .

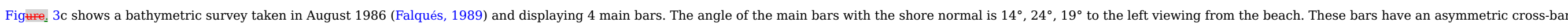

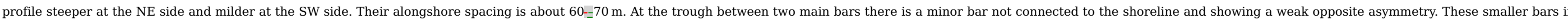

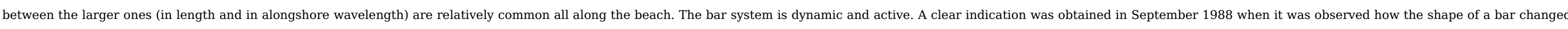

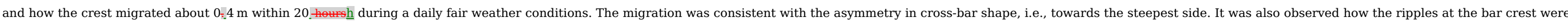
formed, changed the shape and size and disappeared.

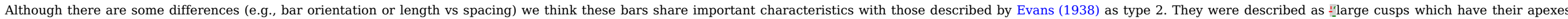




\subsection{Large scale shoreline undulations}

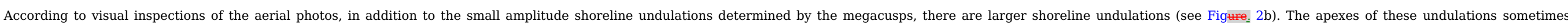

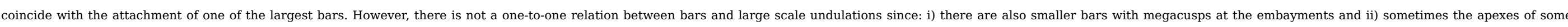

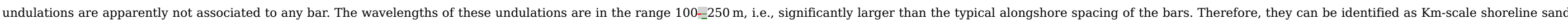
waves although their wavelength is smaller than that of the similar features developing on open ocean beaches.

\section{3 Methods}

\subsubsection{Image processing}

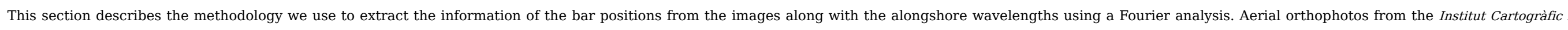
Geologic de Catalunya (ICGC) during the period 1946-_2014 are analyzed to assess the time evolution of the morphology and to obtain its alongshore wavelengths.

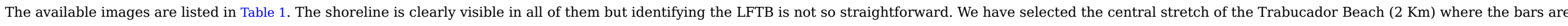

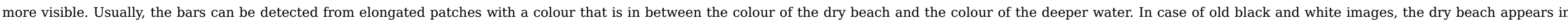

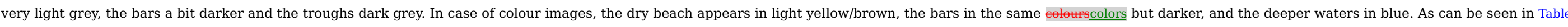

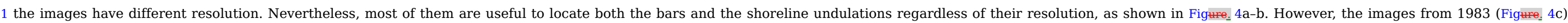

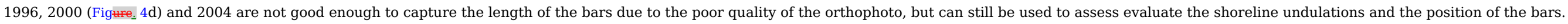

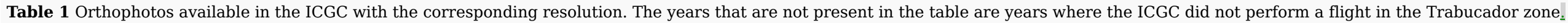
alt-text: Table 1

\begin{tabular}{|c|c|c|c|}
\hline Year & Resolution (cm/px) & LFTB bars & Alongshore Und. \\
\hline 1946 & 100 & YES & YES \\
\hline 1956 & 50 & YES & YES \\
\hline 1983 & 50 & YES & YES \\
\hline 1993 & 2500 & NO & YES \\
\hline 1994 & 50 & YES & YES \\
\hline 1996 & 2500 & NO & YES \\
\hline 2000 & 50 & NO & YES \\
\hline 2004 & 50 & NO & YES \\
\hline 2007 & 50 & YES & YES \\
\hline 2008 & 50 & YES & YES \\
\hline 2009 & 25 & YES & YES \\
\hline 2010 & 25 & YES & YES \\
\hline 2011 & 25 & YES & YES \\
\hline 2012 & 25 & YES & YES \\
\hline
\end{tabular}




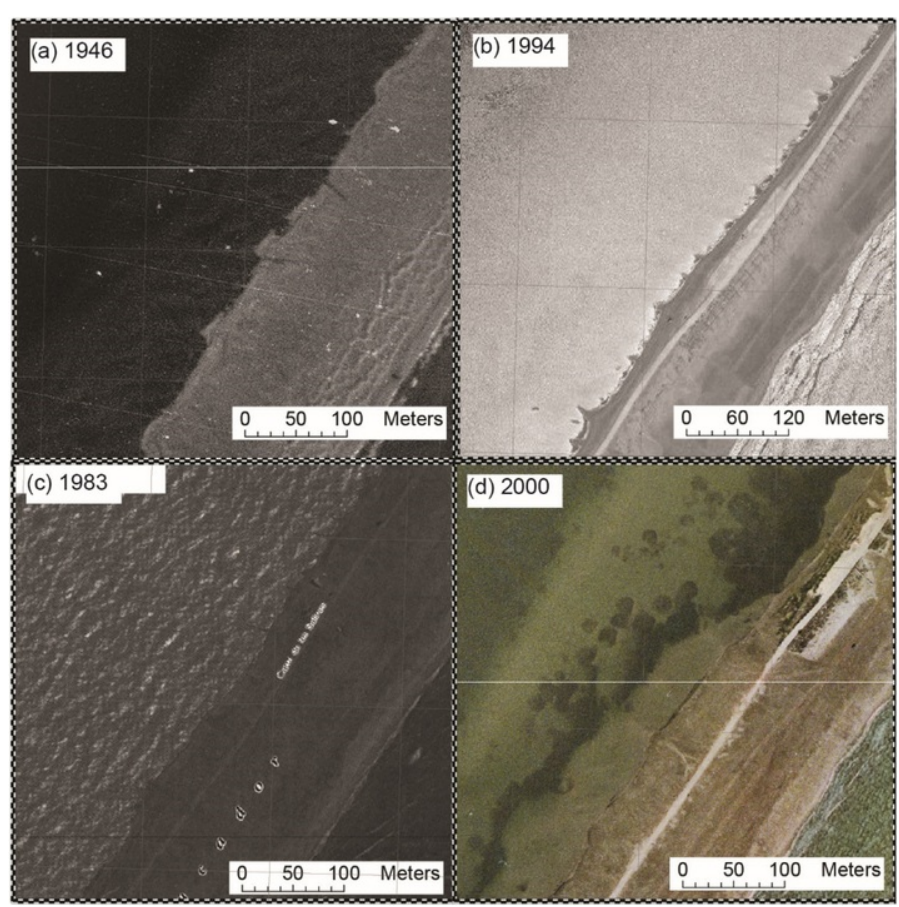

Figure 4Fiq. 4 Zoom in of four orthophotos during different years. a) b) high quality images; c) d) low quality images. Source: ICGC. alt-text: Fig. 4

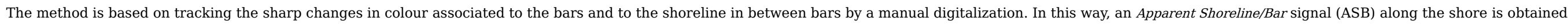

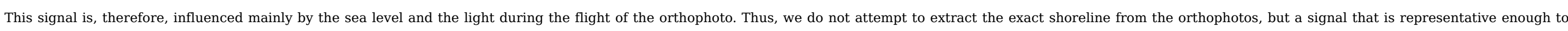

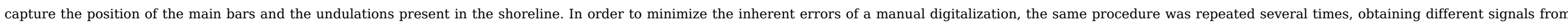

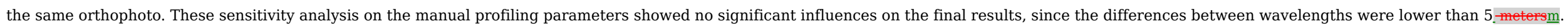

More specifically, the ASB signal is obtained from the images detailed in Table 1 as follows:

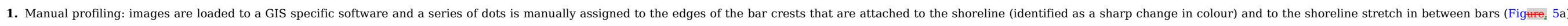

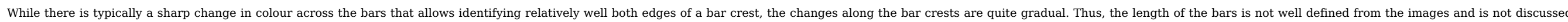

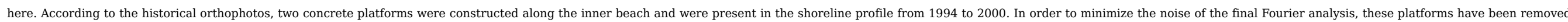
from the original signal.

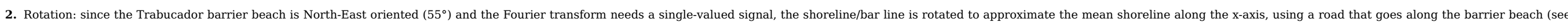
Figure. 5b). However, the bars are still tilted towards the South-West and a single-valued signal is not obtained for all the bars. This creates some problems in the next step.

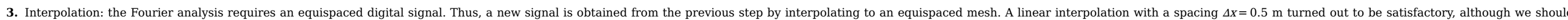

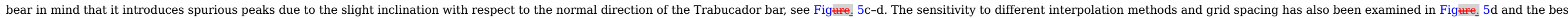



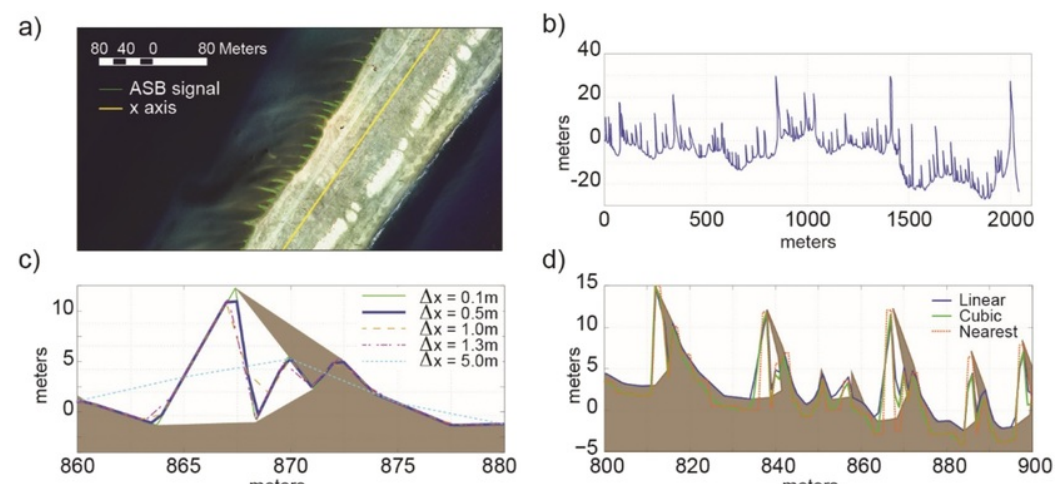

d) 15

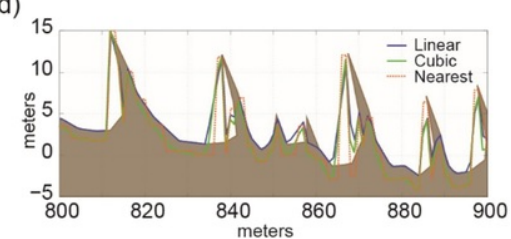

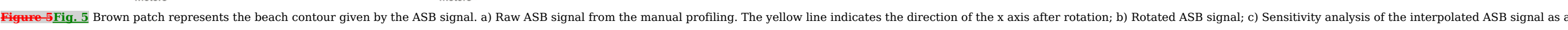

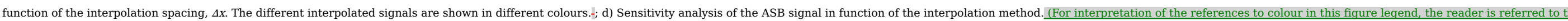
web version of this article.

alt-text: Fig. 5

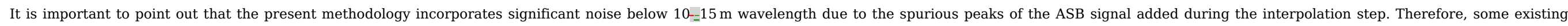
peaks around $10 \mathrm{~m}$ will not be captured accurately using our methodology, as shown in Figmes $5 \mathrm{~d}$. The resulting ASB signals can be seen in Figwre 6 . 


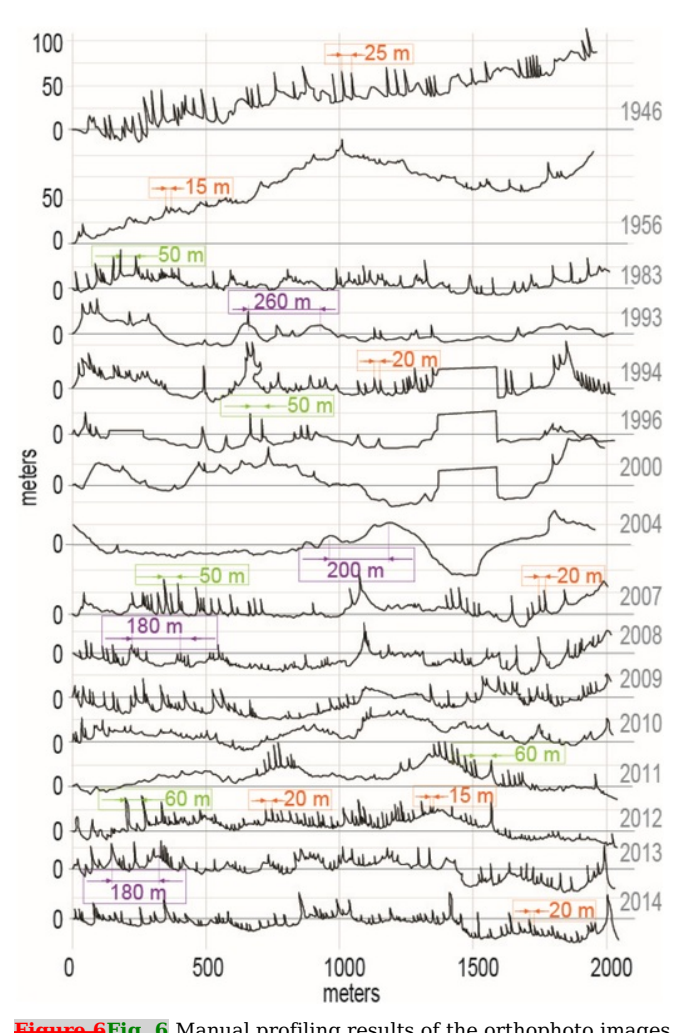

Figure 6Fig. 6 Manual profiling results of the orthophoto images.

\section{alt-text: Fig. 6}

The Discrete Fourier transform of a continuous signal, $f(\xi)$, in the spatial domain is defined by:

$$
f(\xi)=\frac{a_{0}}{2}+\sum_{n=1}^{\infty}\left[a_{n} \cos \left(\frac{2 \pi}{\lambda_{1}} n \xi\right)+b_{n} \sin \left(\frac{2 \pi}{\lambda_{1}} n \xi\right)\right]
$$

where the coefficients are:

$$
\begin{aligned}
& a_{n}=\frac{2}{\lambda_{1}} \int_{0}^{\lambda_{1}} f(\xi) \cos \left(\frac{2 \pi}{\lambda_{1}} n \xi\right) d \xi \\
& b_{n}=\frac{2}{\lambda_{1}} \int_{0}^{\lambda_{1}} f(\xi) \sin \left(\frac{2 \pi}{\lambda_{1}} n \xi\right) d \xi
\end{aligned}
$$

and the energy of each wavenumber is

$$
\left|F_{n}\right|=\sqrt{a_{n}^{2}+b_{n}^{2}}
$$

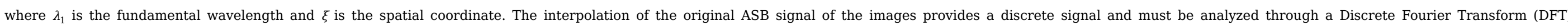

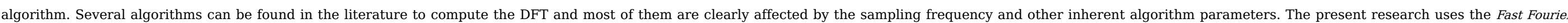

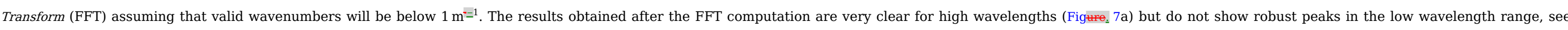

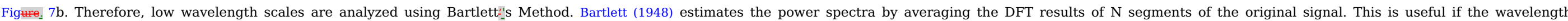

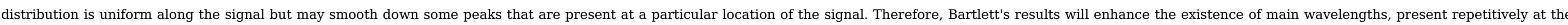


(a)

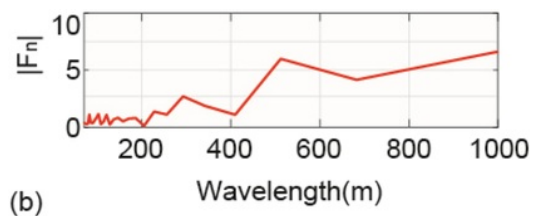

(b)

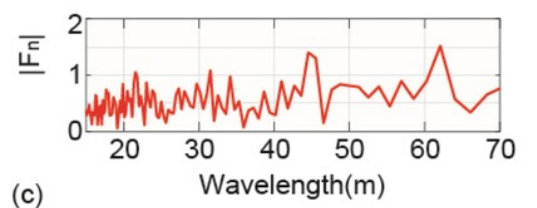

(c)

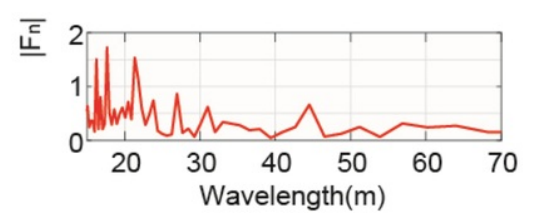

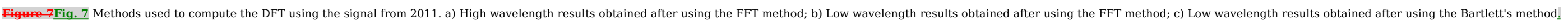
alt-text: Fig. 7

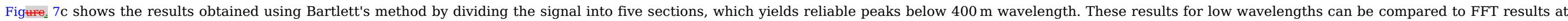

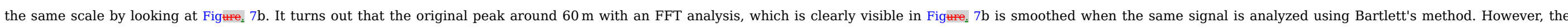

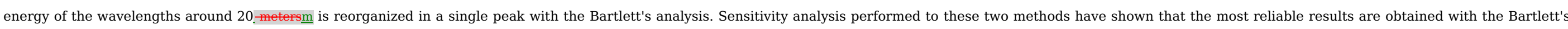

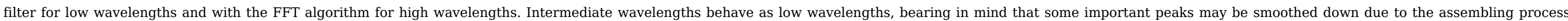
associated to the Bartlett's filter

\subsubsection{Numerical modelling}

This section presents the numerical modelling we have used to investigate the physical mechanisms that could have originated this system and/or could be driving its dynamics at present.

\subsection{Wave field}

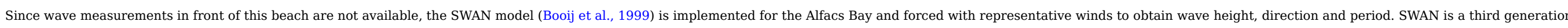

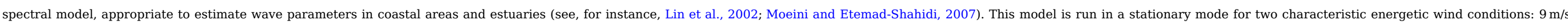

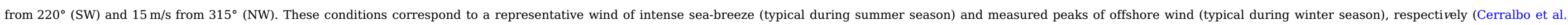
2015a; Grifoll et al., 2016).

\subsection{Morphodynamic instabilities.}

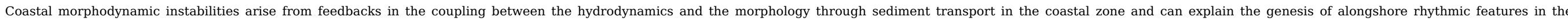

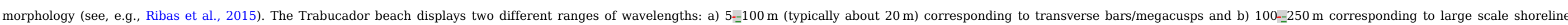

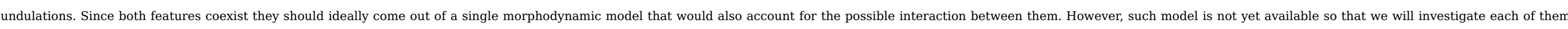
separately. This makes sense because transverse bars can exist in nature in absence of large scale shoreline undulations and vice versa. Therefore, their possible interaction is not essential for their formation. 


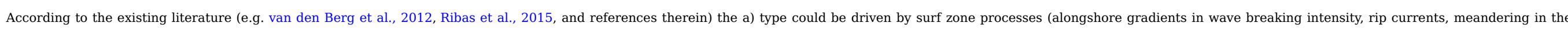

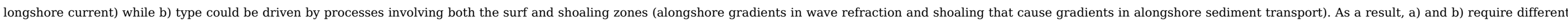

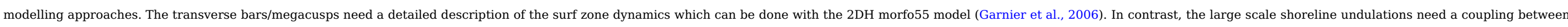

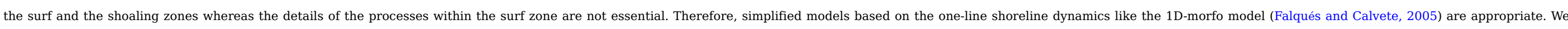
here down describe the basic concepts of these models. The details can be found in the provided references.

Morfo55 (Garnier et al., 2006) is based on the sediment conservation equation in two horizontal dimensions:

$$
\frac{\partial z_{b}}{\partial t}+\frac{\partial q_{x}}{\partial x}+\frac{\partial q_{y}}{\partial y}=0
$$

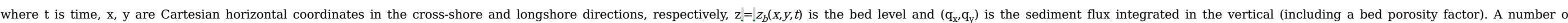
different parameterizations of sediment transport can be used in the model but here we will use

$\vec{q}=C(\vec{v}-\gamma \nabla h)$

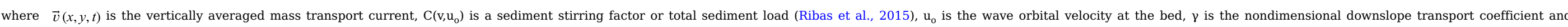

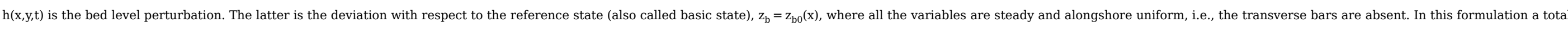

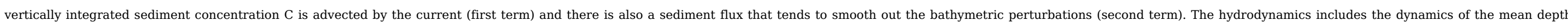

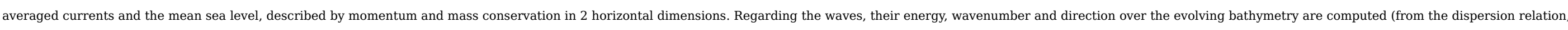

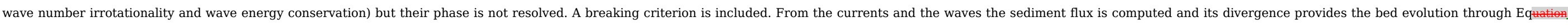

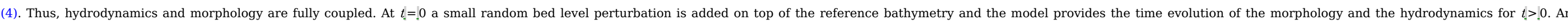

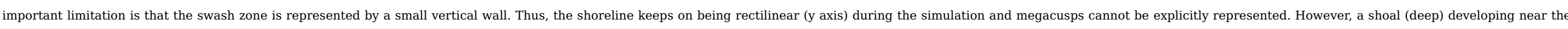

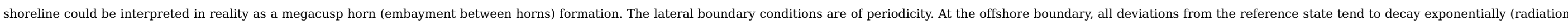

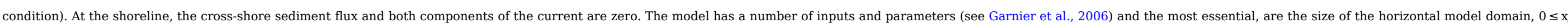

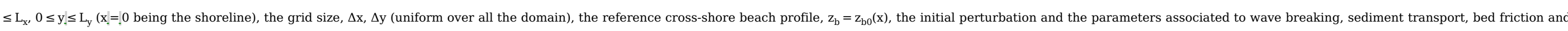

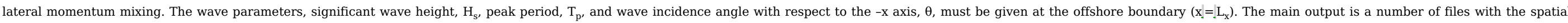
distribution of all variables corresponding to selected times, $t=0, t_{1}, t_{2}, \ldots t_{n}$

In the $1 \mathrm{D}-$-morfo model a small-amplitude sinusoidal undulation is imposed on a reference rectilinear shoreline $(\mathrm{x}=0 \mathrm{0})$ being defined as:

$$
x_{s}(y, \mathrm{t})=\frac{a}{2} \exp (\sigma t+i K y)+c . c
$$

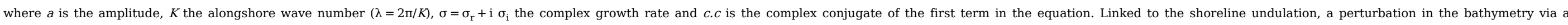

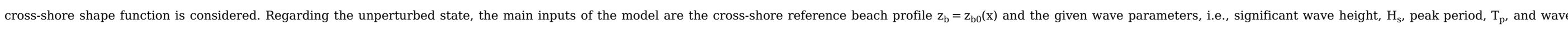

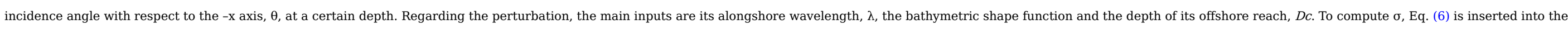
one-line sediment conservation equation (Komar, 1998)

$$
\frac{\partial x_{s}}{\partial t}=\frac{1}{\bar{D}} \frac{\partial Q}{\partial y}
$$

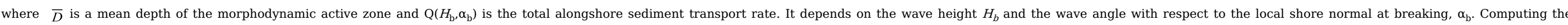

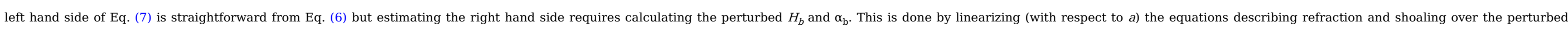

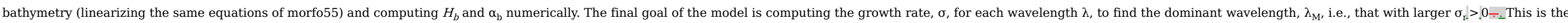
one that grows faster and that should therefore compare well with the observations.

\section{4 Results}




\subsubsection{Image processing}

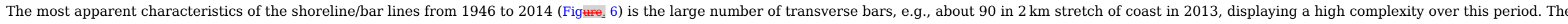

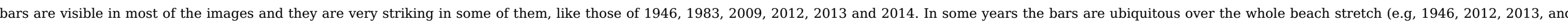

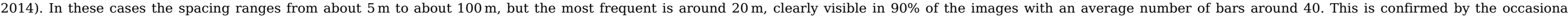

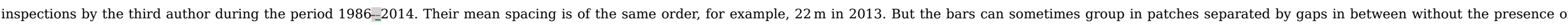

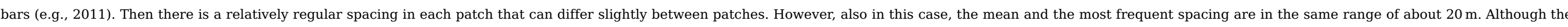

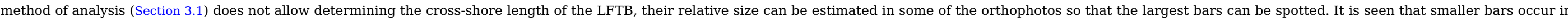

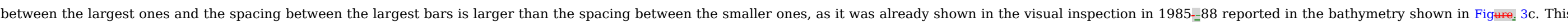

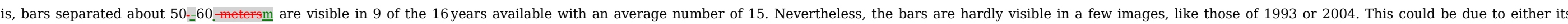
absence in the field or to the bad quality of the images.

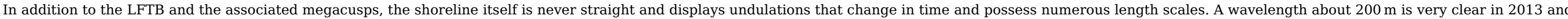

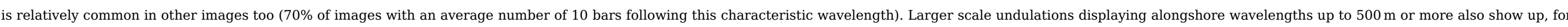
example, in 1956, 2010 and 2011.

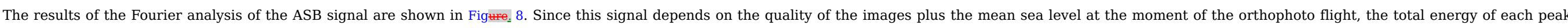
depends also on these characteristics.
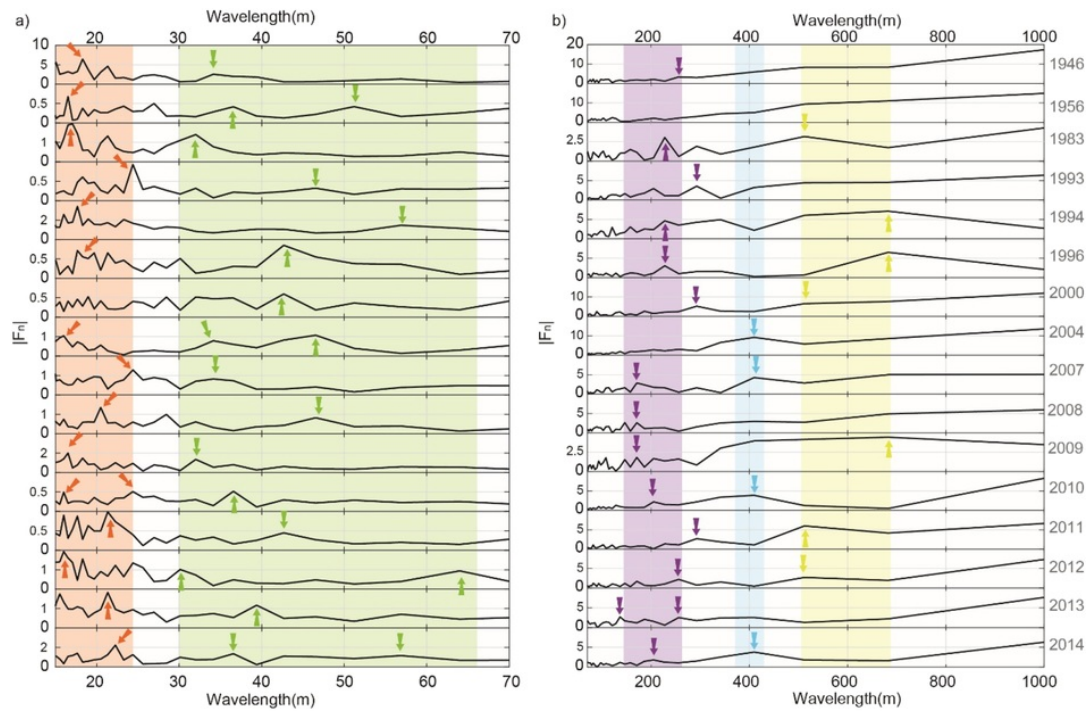

Eigure 8Fig. 8 a) Low wavelength results analyzed using Bartlett's method. b) High wavelength results analyzed using FFT. Notice that the vertical scale is not the same for the different images. alt-text: Fig. 8

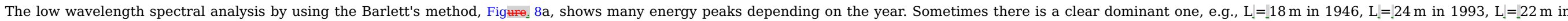
2014. However, more frequently there are several peaks that are comparable in amplitude. What is quite clear is that the energy peaks can be mainly grouped in two bands

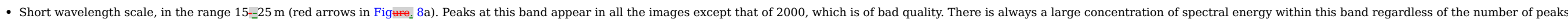
It is directly related to the most common spacing between transverse bars. 
- Medium wavelength scale, in the range 30- $65 \mathrm{~m}$ (green arrows in Figme 8a). It is related to the spacing between the largest LFTB. This is the spacing between LFTB in Figme 3c and was referred to in (Falqués, 1989).

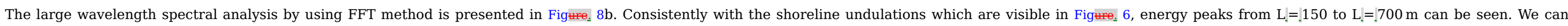
group them in three bands:

- Wavelengths in the range 150-250 m (violet arrows in the plot). These are the most frequent peaks. They can be more clearly seen in 1983, 1996 and 2000, but are present in almost all the images.

- Wavelengths about $400 \mathrm{~m}$ (cyan arrows in the plot). They are less frequent but when they appear they are dominant, for example in 2014.

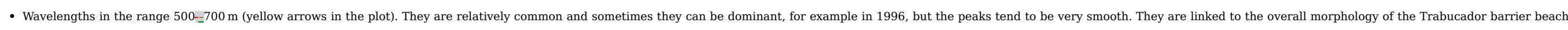
Although the validity of the FFT for these length scales so close to the domain length is arguable, such wavelengths show up for the large scale undulations in Figme. 6 , for example in 1956 or in 2000

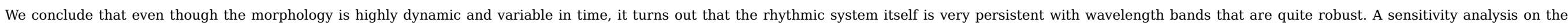
interpolation and FFT methods concluded that wavelengths below 10 meterm were clearly influenced by both.

\subsubsection{Numerical modelling}

\subsection{Wave field}

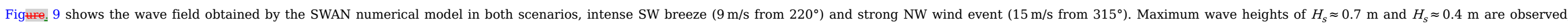

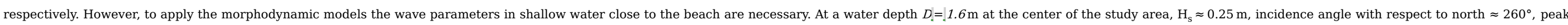

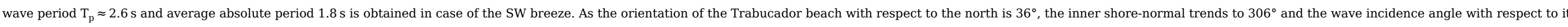
is $\theta \approx 46^{\circ}$. For the $\mathrm{NW}$ event $\mathrm{H}_{\mathrm{s}} \approx 0.65 \mathrm{~m}, \mathrm{~T}_{\mathrm{p}} \approx 3 \mathrm{~s}$ and the incidence angle with respect to north $\approx 305^{\circ}$, i.e., nearly shore-normal.

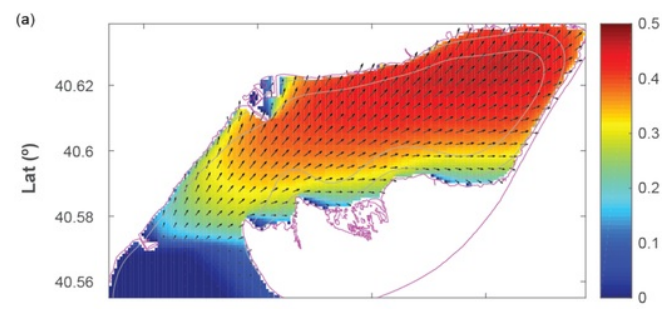

(b)

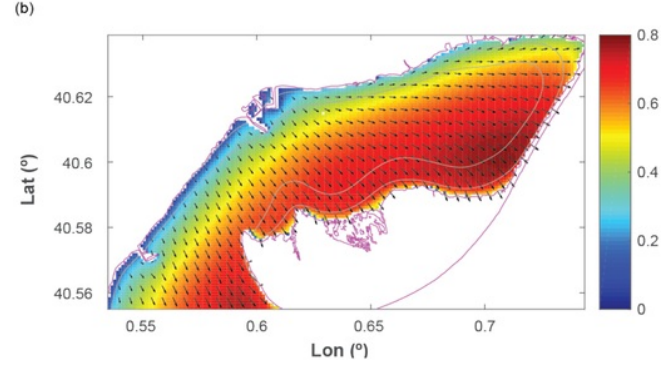

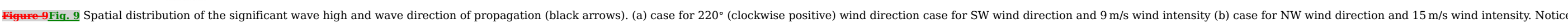
that the bor bolour limits is not the same for the different images.

alt-text: Fig. 9

\subsection{Transverse bars/megacusps}




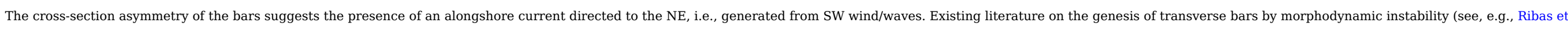

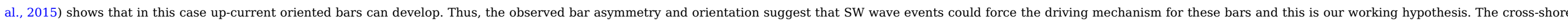

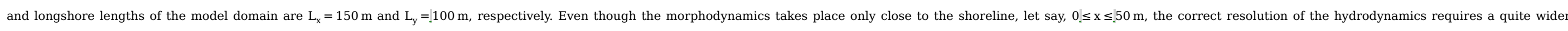

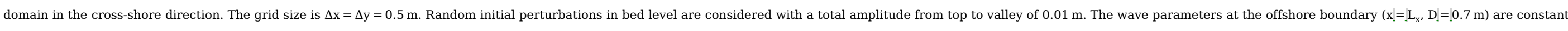

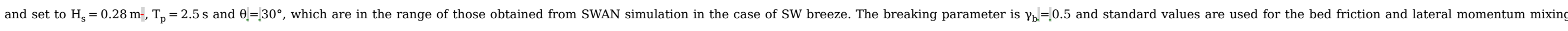

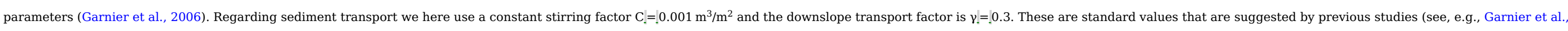
2006).

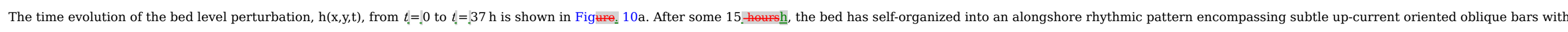

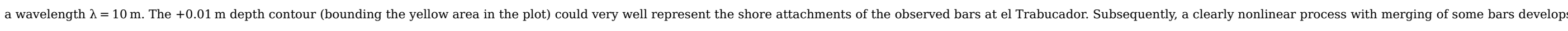

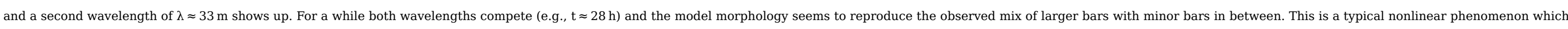

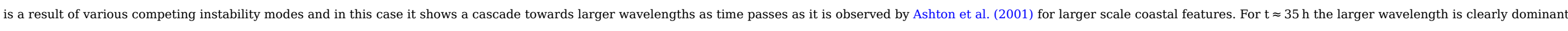

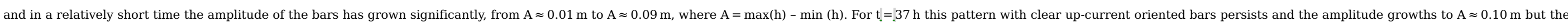

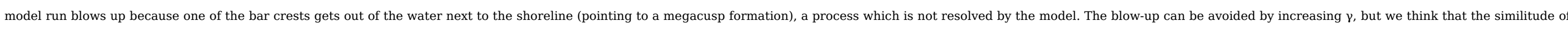

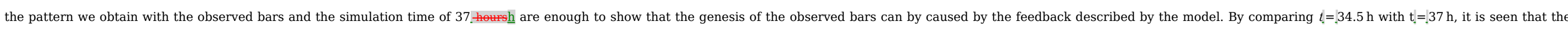

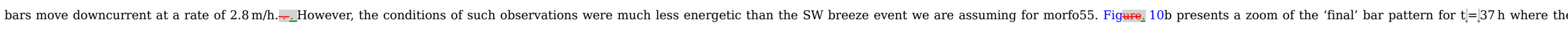

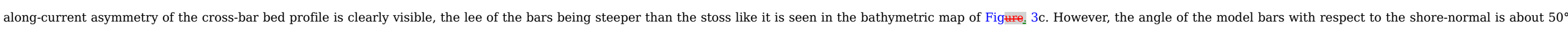

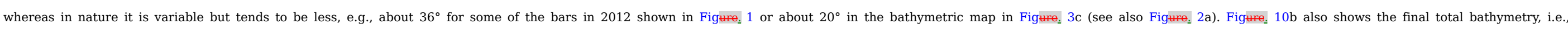

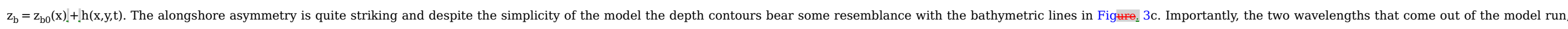
$\lambda=10 \mathrm{~m}$ and $\lambda=33 \mathrm{~m}$ fit very well in the observed wavelength range. 


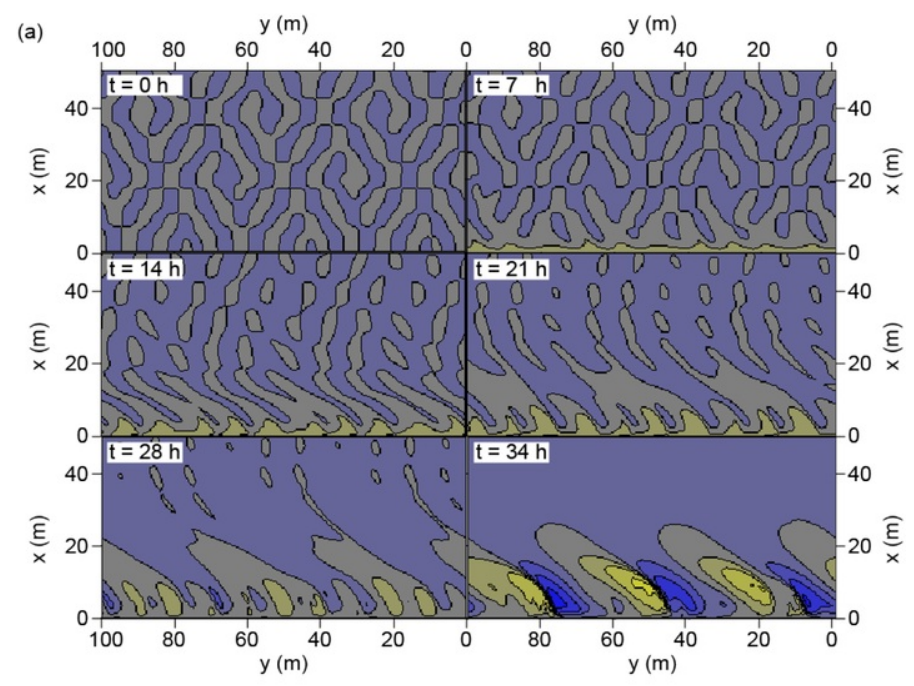

(b)

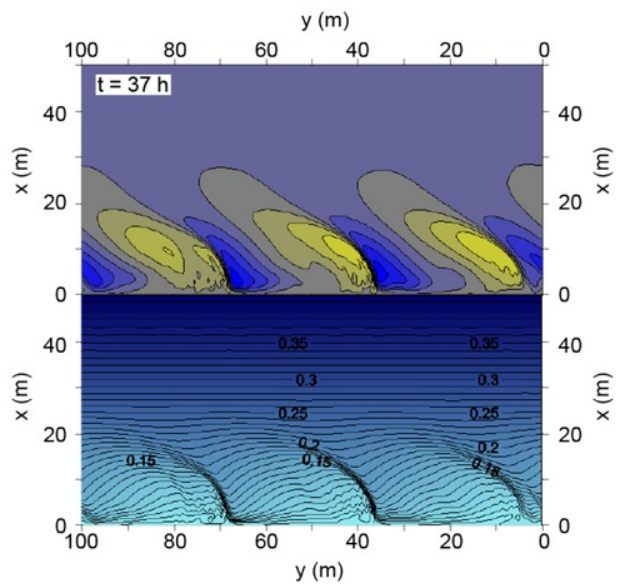

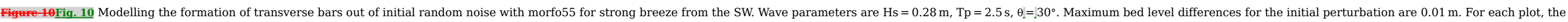

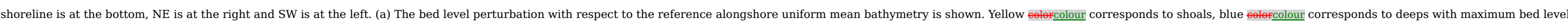

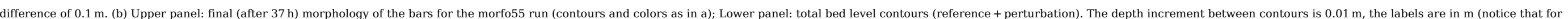
computational reasons the shoreline is not at water depth $\mathrm{D}=0$ but at $\mathrm{D}=0.03 \mathrm{~m}$ ). (For interpretation of the references to colour in this fiqure legend, the reader is referred to the web version of this article..

\subsection{Large scale shoreline undulations}

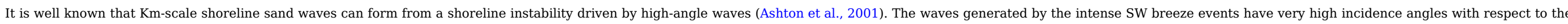

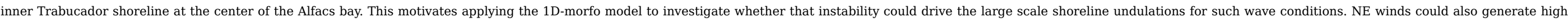

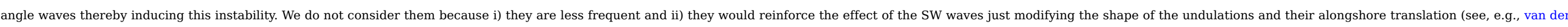
Berg et al., 2012). Regarding the reference cross-shore bathymetric profile, Figure. 11a shows bathymetric data provided by Dr. Guillén (personal communication) and its analytic approximation which is used for the model. 


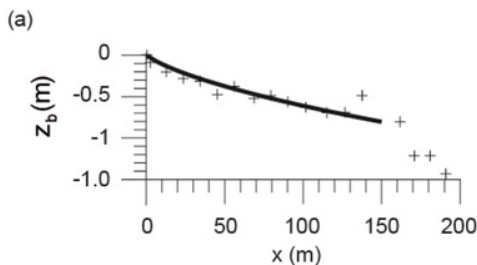

100
$x(m)$

(c)

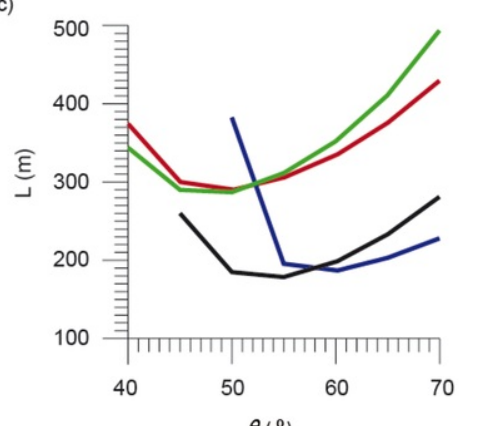

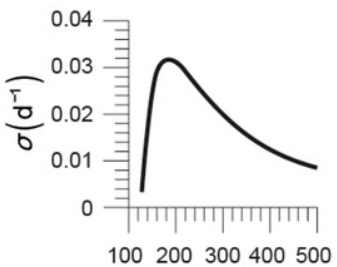

100200300400500

$\mathrm{L}(\mathrm{m})$

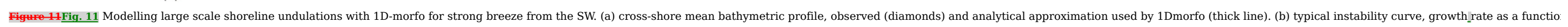

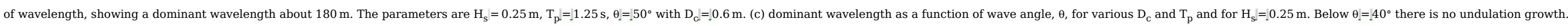
alt-text: Fig. 11

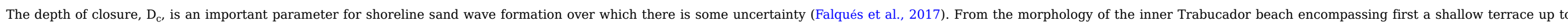

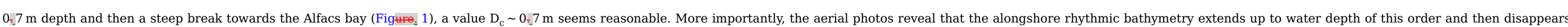

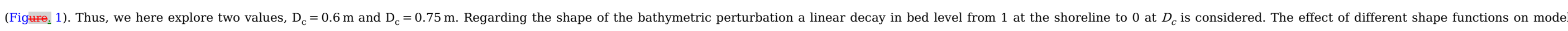

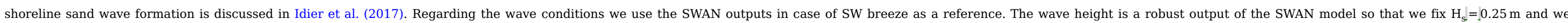

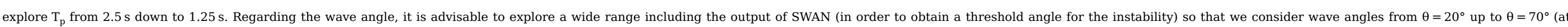

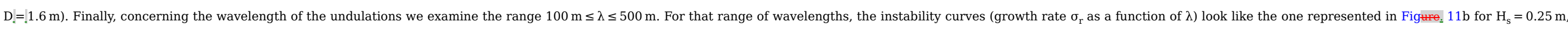

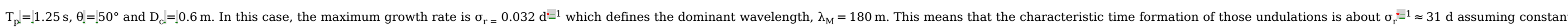

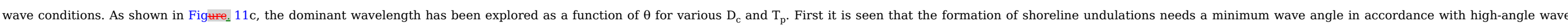

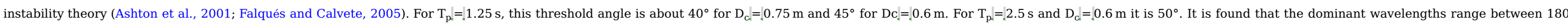

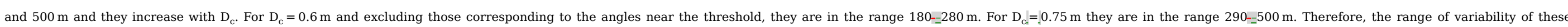

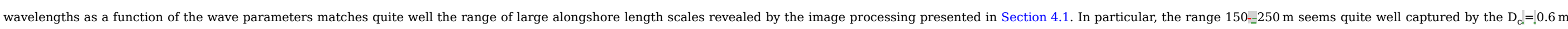

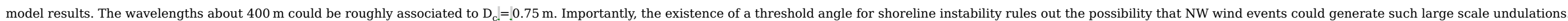

\section{5. $\underline{5}$ Discussion and possible driving mechanisms 5.1.5.1 Morphodynamic characteristics of the observations.}

Previously, it is important to identify some of the characteristics of the morphological system that can provide clues into the driving processes:

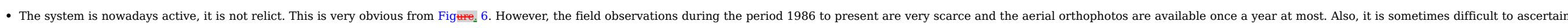
whether the bars are not there or they are simply not visible. Thus, with the available information it is impossible to accurately assess the time variability of the system and try to link it to particular meteorological events. 
- The range of wavelengths (Section 4.1). For the transverse bars/megacusps it is $15-=65 \mathrm{~m}$ and the overall most common is about $20 \mathrm{~m}$. For the large-scale undulations it is about $150=-400 \mathrm{~m}$ but the most typical wavelengths are about $150=-250 \mathrm{~m}$.

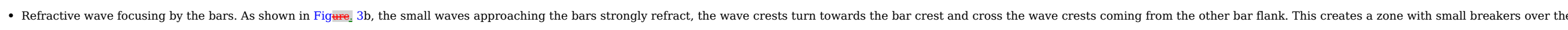

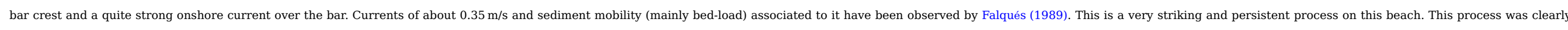
described by Niederoda and Tanner (1970) and was suggested to be one of the driving mechanisms of some transverse bars.

- Obliquity and orientation. According to the aerial photos the bars are not shore normal but oblique, i.e., they are typically rotated to the left viewing from the shore an angle ranging from $10^{\circ}$ to $40^{\circ}$.

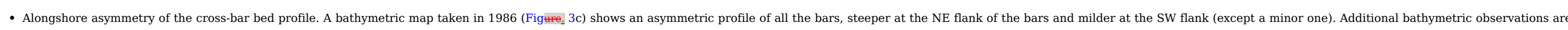

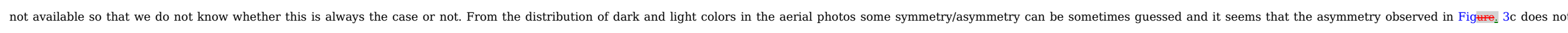
always occur.

\subsubsection{Transverse bars}

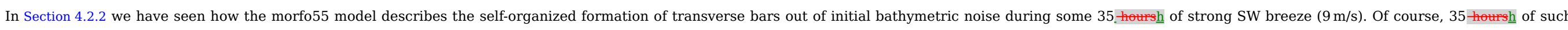

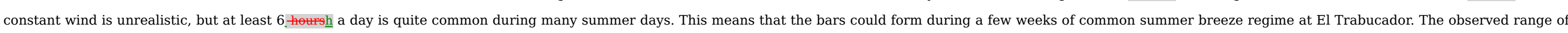

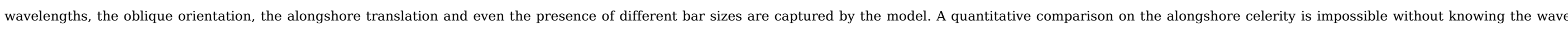

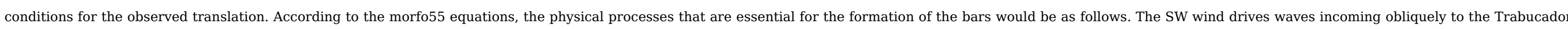

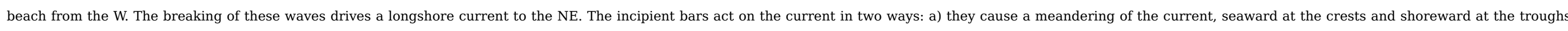

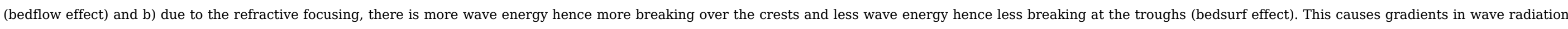

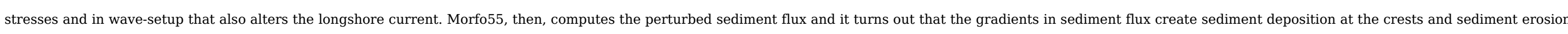

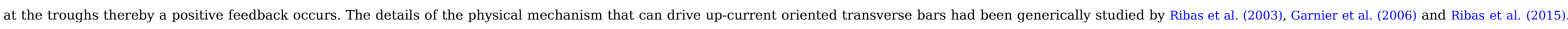

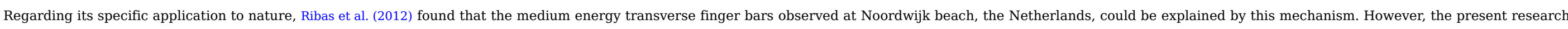

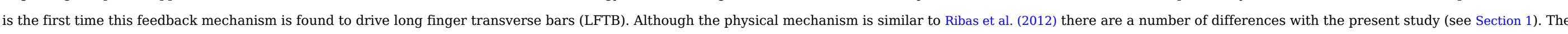

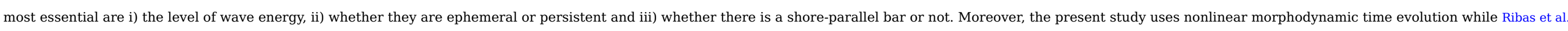

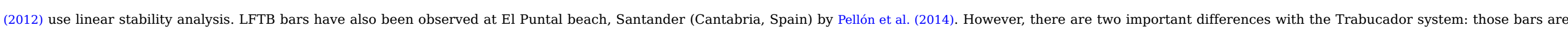
down-current oriented and the tidal range is significant, up to $5 \mathrm{~m}$. Moreover, a morphodynamic modelling of their formation is not available so that their formation mechanism is still unknown.

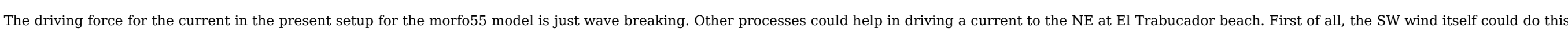

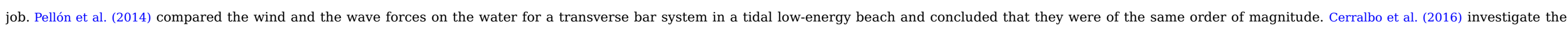

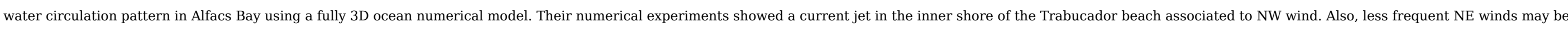

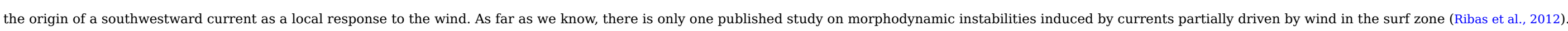

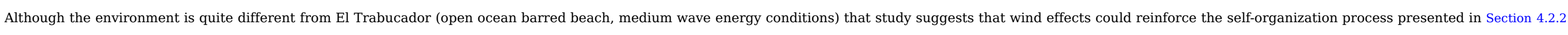
Certainly, more detailed observations are needed along with specific modelling studies on morphodynamic instabilities generated by partially wind-driven current.

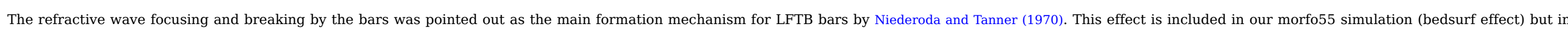

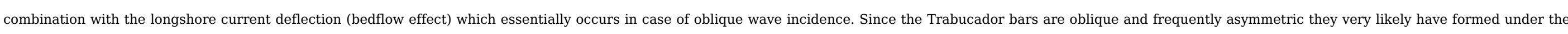

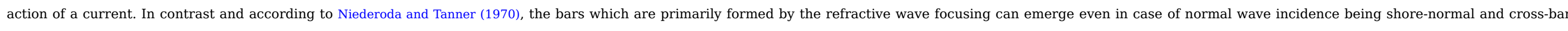
symmetric. Thus, we conclude that the present bars are not formed only by the refractive wave focusing but by the combination of both this process and the longshore current interaction with the bars.

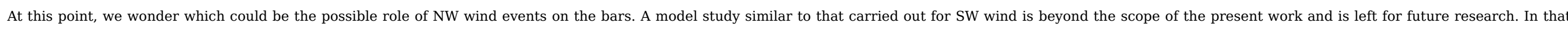

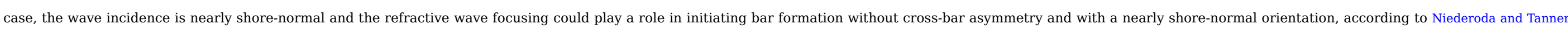

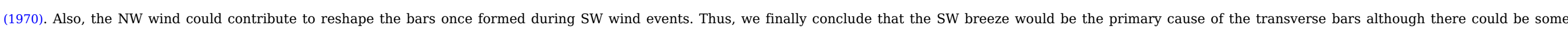




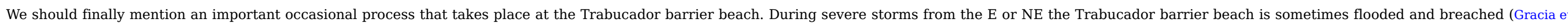

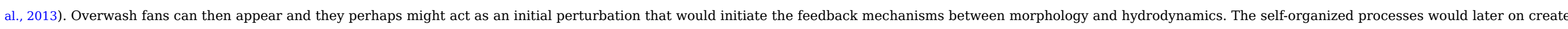
the long finger transverse bars and induce the alongshore periodicity. Since the bars are much thinner than the overwash fans it is unlikely that these fans were the seed for the bars.

\subsubsection{Large-scale shoreline undulations}

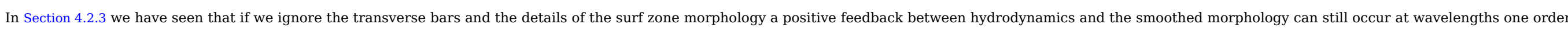

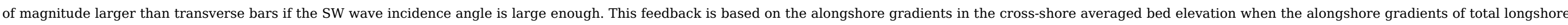

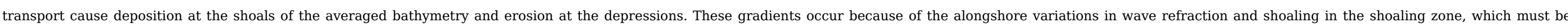

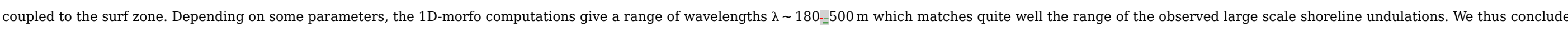
that high-angle wave instability for SW breezes could provide a plausible explanation for the large scale shoreline undulations.

\section{6 Concluding remarks}

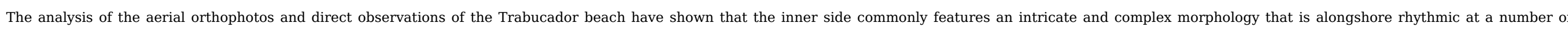

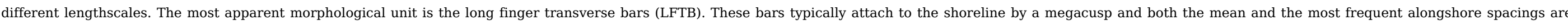

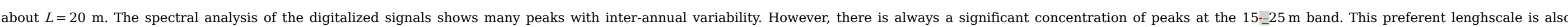

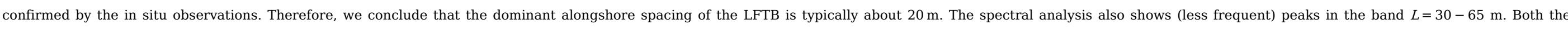
orthophotos and the direct observations show that they correspond to the spacing between the largest bars having minor bars in between.

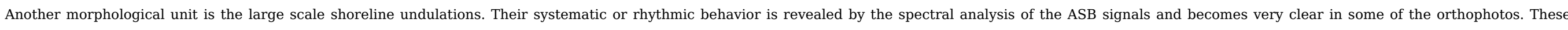

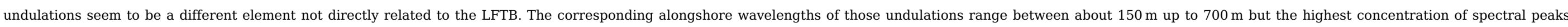
associated to them is around $200 \mathrm{~m}$.

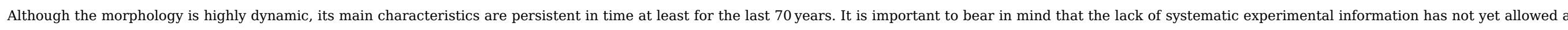

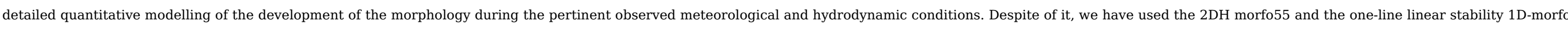

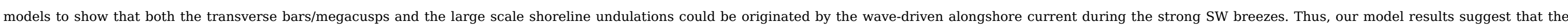

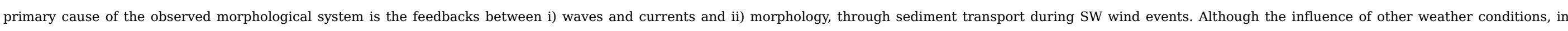

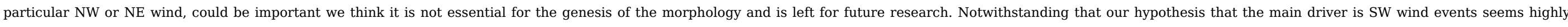

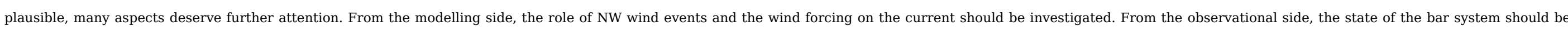

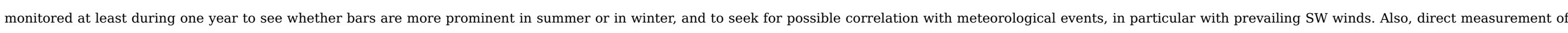

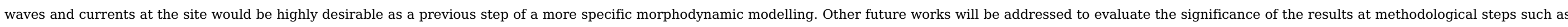
the coastline profiling or the Fourier analysis.

\section{Uncited references}

Calvete et al., 2001

Hallermeier, 1978

\section{Acknowledgements}

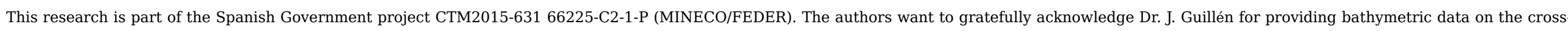

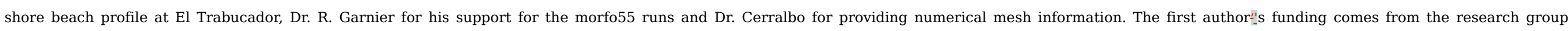




\section{LIM/UPC.}

\section{References}

Ashton A., Murray A.B. and Arnault O., Formation of coastline features by large-scale instabilities induced by high-angle waves, Nature 414, 2001, 296-300.

Bartlett M.S., Smoothing periodograms from time series with continuous spectra, Nature 161, 1948, 686-687.

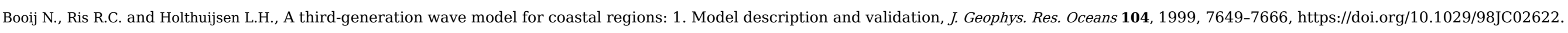
Bruner K.R. and Smosna R.A., The movement and stabilization of beach sand on transverse bars, Assateague Island, Virginia. J. Coast. Res. 5, $1989,593-601$.

Calvete D., Falqués A., de Swart H.E. and Walgreen M., Modelling the formation of shoreface-connected sand ridges on storm-dominated inner shelves, J. Fluid Mech. 441, 2001, 169-193,

https://doi.org/10.1017/S0022112001004815.

Calvete D., Dodd N., Falqués A. and van Leeuwen S.M., Morphological Development of Rip Channel Systems: Normal and Nㅡear Normal Wave Incidence, J. Geophys. Res. 110, 2005.

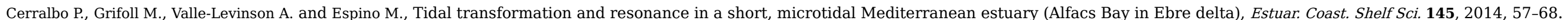

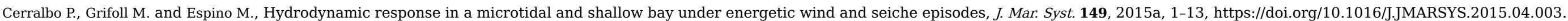

Cerralbo P., Grifoll M., Moré J., Bravo M., Afif A.S. and Espino M., Wind variability in a coastal area (Alfacs Bay, Ebro River delta), Adv. Sci. Res. 12, $2015 b, 11-21$.

Cerralbo P., Espino M. and Grifoll M., Modeling circulation patterns induced by spatial cross-shore wind variability in a small-size coastal embayment, @eean Model.Ocean Model 104, 2016, 84-98,

https://doi.org/10.1016/J.OCEMOD.2016.05.011.

Coco G. and Murray A.B., Patterns in the sand: Ffrom forcing templates to self-organization, Geomorphology $91,2007$.

Coco G., Huntley D.A. and O_:Hare T.J., Investigation of a self-organization model for beach cusp formation and development, J. Geophys. Res. 105, 2000, $21991-22002$.

Deigaard R., Drønen N., Fredsoe J., Jensen J.H. and Jørgensen M.P., A morphological stability analysis for a long straight barred coast, Coast. Eng. 36, 1999 , 171-195.

Dodd N., Stoker A., Calvete D. and Sriariyawat A., On Beach Cusp Formation, J. Fluid Mech. 597, 2008, 145-169.

Evans O.F., The classification and origin of beach cusps, J. Geol. 46, 1938, 615-627.

Evans O.F., Mass transportation of sediments on subaqueous terraces, J. Geol. 47, 1939, 325-334.

Falqués A., Formación de Topografía a rítmica en el Delta del Ebro, Rev. Geofísica 45, 1989, 143-156.

Falqués A. and Calvete D., Large scale dynamics of sandy coastlines. Diffusivity and instability, J. Geophys. Res. $110,2005$.

Falqués A., Coco G. and Huntley D.A., A mechanism for the generation of wave-driven rhythmic patterns in the surf zone, J. Geophys. Res. 105, 2000, $24071-24088$.

Falqués A., Ribas F., Idier D. and Arriaga J., Formation mechanisms for self-organized km-scale shoreline sand waves, J. Geophys. Res. Earth Surf. 2017 , 122.

Garnier R., Calvete D., Falqués A. and Caballeria M., Generation and nonlinear evolution of shore-oblique/transverse sand bars, J. Fluid Mech. 567, 2006, 327-360.

Garnier R., Calvete D., Falqués A. and Dodd N., Modelling the formation and the long-term behavior of rip channel systems from the deformation of a longshore bar, J. Geophys. Res. 113, 2008.

Gelfenbaum G. and Brooks G.R., The morphology and migration of transverse bars off the west-central Florida coast, Mar. Geol. 200, 2003, 273-289.

Gracia V., Garcia M., Grifoll M. and Sánchez-Arcilla A., Breaching of a barrier under extreme events. The role of morphodynamic simulations, J. Coast. Res. 65, 2013, 951-956. 
Grifoll M., Aretxabaleta A.L. and Espino M., Shelf response to intense offshore wind, J. Geophys. Res. Oceans 120, 2015.

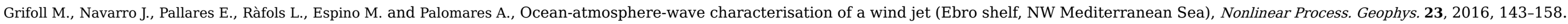

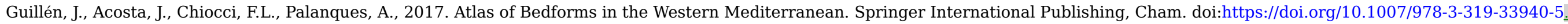
Hallermeier, R.J., 1978. Uses for a calculated limit depth to beach erosion, in: Coastal Eng. 1978. Am. Soc. of Civ. Eng., pp. $1493-1512$.

Holman R.A. and Bowen A.J., Bars, bumps, and holes: models for the generation of complex beach topography, J. Geophys. Res. 87, 1982, 457-468.

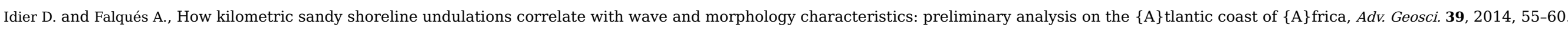
Idier D., Falqués A., Rohmer J. and Arriaga J., Self-organized kilometre-scale shoreline sandwave generation: sensitivity to model and physical parameters, J. Geophys. Res. 122, 2017.

Jiménez J., Sánchez-Arcilla A., Valdemoro H.I., Gracia V. and Nieto F., Processes reshaping the Ebro delta, Mar. Geol. 144, 1997, 59-79, https://doi.org/10.1016/S0025-3227(97)00076-5.

Kaergaard K. and Fredsoe J., Numerical modeling of shoreline undulations part 1: Gconstant wave climate, Coast. Eng. 75, 2013, 64-76.

Khabidov, A., 2001. Transverse bars formation on a tideless beach, in: of Civil Engineers. Lund, S. (Ed.), Proceedings Coastal Dynamics 2001. p 1 p. 666-672.

Komar P.D., Beach \{P\}rocesses and \{S\}edimentation, Second. ed., 1998, Prentice Hall; Englewood Cliffs, N.J.

Konicki K.M. and Holman R.A., The statistics and kinematics of transverse bars on an open coast, Mar. Geol. 169, 2000, 69-101.

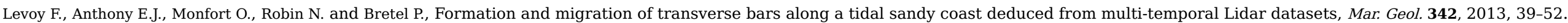

Lin W., Sanford L.P. and Suttles S.E., Wave measurement and modeling in Chesapeake Bay, Cont. Shelf Res. 18, 2002, 2673-2686.

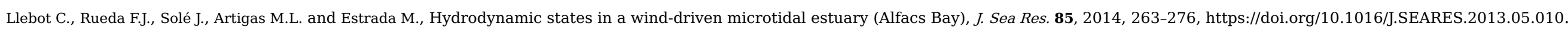

Moeini M.H. and Etemad-Shahidi A., Application of two numerical models for wave hindcasting in Lake Erie, Appl. Ocean Res. 29, 2007, 137-145.

Niederoda A.W. and Tanner W.F., Preliminary study on transverse bars, Mar. Geol. 9, 1970, 41-62.

Nienhuis J.H.J.H., Ashton A.D.A.D., Kettner A.J.A.J. and Giosan L., Large-scale coastal and fluvial models constrain the late Holocene evolution of the Ebro Delta, Earth Surf. Dyn. 5, 2017 , 585-603.

Palacin C., Martin D. and Gili J.M., Features of spatial distribution of benthic in fauna in a Mediterranean shallow-water bay, Mar. Biol. 110, 1991, 315-321.

Pellón E., Garnier R. and Medina R., Intertidal finger bars at El Puntal spit, Bay of Santander, Spain: observation and forcing analysis, Earth Surf. Dyn. 2, 2014 , 349-361.

Pritchard, A., 1952. Estuarine Hydrography. Advances in Geophysics, vol. 1. Academic Press, Inc., New York, USA.

Ribas F. and Kroon A., Characteristics and dynamics of surfzone transverse finger bars, J. Geophys. Res. 112, 2007.

Ribas F., Falqués A. and Montoto A., Nearshore oblique sand bars, J. Geophys. Res. 108, 2003.

Ribas F., de Swart H.E., Calvete D. and Falqués A., Modeling and analyzing observed transverse sand bars in the surf zone, J. Geophys. Res. 117, 2012.

Ribas F., Falqués A., de Swart H.E., Dodd N., Garnier R. and Calvete D., Understanding coastal morphodynamic patterns from depth-averaged sediment concentration, Rev. Geophys. 53, 2015.

Shepard F.P., Revised nomenclature for depositional coastal features, Bull. Am. Assoc. Pet. Geol. 36, 1952, 1902-1912.

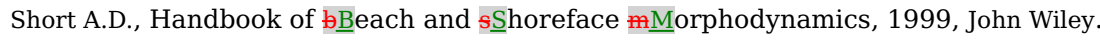

van den Berg N., Falqués A. and Ribas F., Modelling large scale shoreline sand waves under oblique wave incidence, J. Geophys. Res. 117, 2012. 